\title{
STOTZ, Peter, Handbuch zur lateinischen Sprache des Mittelalters, t. 3 : Lautlehre
}

\section{Monique Goullet}

\section{OpenEdition}

\section{Journals}

Édition électronique

URL : http://journals.openedition.org/ifha/1465

DOl : 10.4000/ifha. 1465

ISSN : 2198-8943

Éditeur

IFRA - Institut franco-allemand (sciences historiques et sociales)

Référence électronique

Monique Goullet, «STOTZ, Peter, Handbuch zur lateinischen Sprache des Mittelalters, t. 3 : Lautlehre», Revue de I'IFHA [En ligne], Date de recension, mis en ligne le 01 janvier 1998, consulté le 22 septembre 2020. URL : http://journals.openedition.org/ifha/1465 ; DOI : https://doi.org/10.4000/ifha.1465

Ce document a été généré automatiquement le 22 septembre 2020

(CIFHA 


\title{
STOTZ, Peter, Handbuch zur lateinischen Sprache des Mittelalters, $t$. 3 : Lautlehre
}

\author{
Monique Goullet
}

Il n'existe à ce jour aucune grammaire du latin médiéval: aussi l'entreprise de P.S. étaitelle particulièrement attendue. Lorsqu'elle sera achevée, elle comprendra cinq volumes: les deux premiers sont consacrés aux questions de lexicologie; le troisième à la phonétique; le quatrième, à paraître, traitera de la morphologie, syntaxe et stylistique; le dernier fournira une bibliographie, un répertoire des sources et les indices. Le projet est gigantesque, car il remet à plat tous les résultats d'une recherche jusqu'alors dispersée et parcellaire; il se voudrait néanmoins accessible à un novice. Ce dernier sera certainement découragé devant un volume de 352 pages entièrement consacrées à des questions de phonétique, qu'il pourrait considérer comme de la pure érudition: il aura tort, car P.S. a réussi l'exploit de faire de cette somme une image très vivante de la pratique médiévale. En effet, il ne s'appuie que très sélectivement sur les ouvrages théoriques de Cassiodore, Alcuin, Abbon, etc., et recherche moins à expliquer les phénomènes phonétiques par des lois qui eussent semblé indigestes, qu'il ne décrit les réalités auxquelles est sans cesse confronté le lecteur de textes médiévaux; tout chercheur amené à utiliser des manuscrits latins médiévaux fera son miel de ce manuel. Le plus intéressant, de ce point de vue, est certainement la grande attention portée aux rapports entre écrit et oral: l'une des meilleures sources de notre connaissance de la prononciation médiolatine se trouve précisément dans les écarts de l'orthographie par rapport à la norme classique; l'évolution de la prononciation est inscrite dans la partie écrite. On trouve dans ce livre des clés pour comprendre des formes que l'on aurait un peu trop rapidement imputées à des étourderies de copistes, par exemple l'orthographe eum pour aevum, pour les phénomènes très répandus d'haplologie (idolatria pour idololatria). Chaque forme étudiée faisant l'objet d'une référence très précise en note, gageons que ce livre deviendra rapidement la bible des éditeurs de textes. 
On ne peut bien entendu résumer ce manuel, dont la science et la clarté de P.S. font un véritable trésor. Il fait désormais partie des meilleurs outils du médiéviste, philologue et historien, qui attend avec plus d'impatience encore la parution du volume suivant.

Monique GOULLET 